\title{
Remaining dentine thickness following preparation with different glide path techniques in combination with WaveOne Gold Primary File
}

SADJ November 2019, Vol. 74 No. 10 p534 - p537

M Vorster ${ }^{1}$, PJ van der Vyver², F Paleker ${ }^{3}$

\section{SUMMARY}

\section{Introduction}

This study compared minimum remaining dentine thickness values after different glide path preparation techniques, in combination with WaveOne Gold Primary (PWOG) for final canal instrumentation.

\section{Methods}

Mesiobuccal canals of 60 extracted human mandibular molars were selected and randomly divided into four groups (15 canals each). Canals were brought to patency with a \# $08 \mathrm{~K}$-file before glide path preparation, which was performed by a single operator.

KF group: pre-curved \#10-15-20 stainless steel manual K-files; PF group: \#10 stainless steel manual K-file followed by PathFiles \#1-3; WOGG group: \#10 stainless steel manual K-file followed by WaveOne Gold Glider; and NG group: no further glide path preparation.

Minimum remaining dentine thicknesses were determined on Micro-Computed Tomography scans at levels $3 \mathrm{~mm}, 5 \mathrm{~mm}$ and $7 \mathrm{~mm}$ from the root apex after glide path preparation and again after final preparation with PWOG. One-way analysis of variance (ANOVA) was used to statistically compare groups.

\section{Author affiliations:}

1. Martin Vorster: BChD, PG Dip Dent (Endo), MSc (Pret), Department of Odontology, School of Dentistry, University of Pretoria, Pretoria, South Africa.

ORCID Number: 0000-0003-4470-1530

2. Peet J van der Vyver: BChD, PG Dip Dent (Endo), PG Dip Dent (Aesthet Dent), MSc, PhD (Pret), Department of Odontology, School of Dentistry, University of Pretoria, Pretoria, South Africa. ORCID Number: 0000-0003-1951-6042

3. Farzana Paleker: BChD (Stell), Dip Odont (Endo), MSc (Pret), Department of Odontology, School of Dentistry, University of Pretoria, Pretoria, South Africa.

ORCID Number: 0000-0002-5446-309X

Corresponding author: Martin Vorster

Department of Odontology, School of Dentistry, University of Pretoria,

Pretoria, South Africa.

Email: martin.vorster@up.ac.za

Author contributions:

1. Martin Vorster: Responsible for data collection, analysis and scientific writing - 50\%

2. Peet $\mathbf{J}$ van der Vyver: Responsible for scientific writing and editing $-30 \%$

3. Farzana Paleker: Responsible for editing and layout $-20 \%$
Results

No statistically significant differences $(p<0.05)$ were found amongst the groups.

\section{Conclusion}

The least dentine preservation was seen in the group with no glide path preparation prior to PWOG instrumentation. Within the limitations of the study, all the glide path groups in combination with the PWOG instrument seemed to preserve dentine thickness adequately.

\section{INTRODUCTION}

Prevention and elimination of periapical inflammation is one of the main objectives of endodontic treatment. ${ }^{1}$ Microbial infection and invasion of the endodontic system remains the main cause of radicular and periradicular pathology. ${ }^{2}$ Preserving the position and the size of the apical foramen is another important aspect of canal preparation. ${ }^{3}$

Maintaining the original canal anatomy of a root canal system is critical to the successful shaping of a root canal. Identification and accessing of main canals, establishing and maintaining working length, and geometric considerations concerning instrument size selection while a root canal is being prepared remain some of the most challenging and controversial aspects of endodontic treatment. ${ }^{4}$

Deviation from the canal axis will result in apical transportation, ${ }^{5}$ leading to large areas of the canal being left unprepared. Preserving original canal anatomy and dentine thickness also improves the outcome of endodontic treatment. ${ }^{6}$ For this reason it is important to investigate the ability of a file system to preserve the original shape of the root canal with conservative dentine removal.

Nickel-Titanium (NiTi) files were first introduced into the market for use in endodontics in $1988 .^{7}$ Prior to the use of $\mathrm{NiTi}$ endodontic instruments, canal shaping was performed mainly by stainless steel and carbon instruments. 
Compared with stainless-steel endodontic instruments, $\mathrm{NiTi}$ instruments can endure higher torsional stress, reduce canal preparation time, and reduce the incidence of procedural accidents. ${ }^{7}$ These unique qualities of $\mathrm{NiTi}$ also allow for consistent, efficient shaping with the use of fewer preparation instruments. ${ }^{8}$

Maintaining a smooth reproducible glide path when successive files are used is an important characteristic of proper glide path preparation. ${ }^{9}$ A glide path is defined as a smooth tunnel extending from the canal orifice to the radiographic terminus or exit as determined by the electronic apex locator. ${ }^{10}$

Micro-Computed Tomography (micro-CT), together with histological sections, plastic model evaluation, serial sectioning and radiographic comparisons, has been used to evaluate $\mathrm{NiTi}$ prepared root canals between different systems. ${ }^{11-14}$ Extensive information can be obtained from micro-CT evaluation, as internal and external structures can also be assessed either simultaneously or separately. ${ }^{15,16}$

The aim of this study was to evaluate the effect of different glide path/no glide path techniques in combination with the WaveOne Gold Primary instrument (Dentsply Sirona, Ballaigues, Switzerland) on the remaining dentine thickness after canal preparation in curved mandibular molar root canals.

\section{MATERIALS AND METHODS}

Sixty extracted mandibular first molars with two separate mesial canals and two separate mesial apical foramina were selected. Only previously untreated first mandibular molars with mesiobuccal root canals with curvatures between 25 and 35 degrees were used. The Schneider method was used to evaluate each canal curvature. ${ }^{17}$

After specimens were coded and randomly divided into four groups $(n=15)$, access cavity preparation was done with an Endo-Access bur (Dentsply Sirona). The mesial canals were explored with a size 0.8 K-file (Dentsply Sirona) and canals were negotiated to patency. Working length was determined under a surgical microscope (Zumax Medical Co. Ltd, Suzhou, China) by subtracting $0.5 \mathrm{~mm}$ from the length of the canal measured to the major apical terminus.

\section{Glide path preparation}

Glide path preparation was performed by a single operator in strict accordance with the manufacturer's recommendations for each system. All rotary or reciprocating files were operated by a 16:1 gear reduction hand piece powered by the X.Smart IQ (Dentsply Sirona) cordless motor. RC Prep (Premier, Pennsylvania, USA) was used as a lubricating agent and $3 \%$ sodium hypochlorite (NaOCl) (Jik, Rekitt Benckiser, South Africa) for root canal irrigation.

\section{KF group}

For each canal $(n=15)$ a glide path was prepared using pre-curved size $0.10,0.15$ and 0.20 stainless steel
K-files (Dentsply Sirona). Glide path preparation up to an ISO size 0.20 was confirmed when the stainless steel size $0.20 \mathrm{~K}$-file could be placed at working length, pulled backwards for $4 \mathrm{~mm}$ and pushed back with light finger pressure to full working length without any interference or obstruction.

\section{PF group}

For each canal in this group $(n=15)$ a pre-curved stainless steel size $0.10 \mathrm{~K}$-file was negotiated to working length with increasing amplitudes of $1-3 \mathrm{~mm}$ to ensure an initial manually reproducible glide path. Path Files no. 1-3 (Dentsply Sirona) were used to enlarge each canal in this group.

\section{WOGG group}

For each canal in this group $(n=15)$ a pre-curved stainless steel size $0.10 \mathrm{~K}$-file was negotiated to working length with increasing amplitudes of $1-3 \mathrm{~mm}$ to ensure an initial manually reproducible glide path. The WaveOne Gold Glider (Dentsply Sirona) was then used to enlarge each canal in this group.

\section{NG group}

No preparation was done after initial canal negotiation with a size $0.8 \mathrm{~K}$-file $(n=15)$.

After glide path preparation, the Primary WaveOne Gold (Dentsply Sirona) reciprocating instrument was used for final canal preparation on all 60 canals up to working length.

Shaping was done according to the manufacturer's instructions, using the X.Smart IQ (Dentsply Sirona) cordless motor. Each reciprocating file was used to prepare only one canal before being discarded.

Throughout the instrumentation process RC Prep was used as a lubricant and $5 \mathrm{ml}$ of $3 \%$ sodium hypochlorite was used as irrigation solution.

Micro-CT (XT 225 ST micro-focus X-ray tomography system (Nikon Metrology, Leuven, Belgium)) was used to evaluate the thinnest dentine wall on three different levels before and after glide path instrumentation, as well as after final preparation with the Primary WaveOne Gold instrument.

The shortest distance from the prepared canal to the mesial or distal wall of the tooth at three different levels from the root apex was measured. The side where the remaining dentine thickness was the thinnest was recorded and compared with the other measurements.

\section{Statistical analysis}

Mean and standard deviations were determined for each group and analysis of variance was used to statistically compare the mean remaining dentine thicknesses after glide path and again after final preparation with the Primary WaveOne Gold between the different preparation groups. 
Statistical procedures were performed on SAS Release 9.3 (SAS Institute Inc., Cary, NC) running under Microsoft Windows (Microsoft Corp., Redmond, WA) for a personal computer.

\section{RESULTS}

For each canal the minimum remaining dentine thickness was measured on levels $3 \mathrm{~mm}, 5 \mathrm{~mm}$ and $7 \mathrm{~mm}$ from the anatomical apex after glide path preparation as well as after final preparation with the WaveOne Gold Primary instrument.

Figure 1 illustrates the minimum remaining dentine thickness in the mesiobuccal canals after glide path preparation with the three different glide path preparation techniques.

Figure 2 illustrates the minimum remaining dentine thickness after final preparation with the WaveOne Gold Primary instrument in combination with the different glide path/no glide path preparation techniques.

Combined statistics for minimum remaining dentine thickness over the three levels measured after glide path preparation as well as after final preparation with the Primary WaveOne Gold instrument are presented in Tables 1 and 2.

\section{DISCUSSION}

No significant difference was found at the three levels from the root apex between the different glide path preparation groups when minimum remaining dentine thickness was compared across different groups.

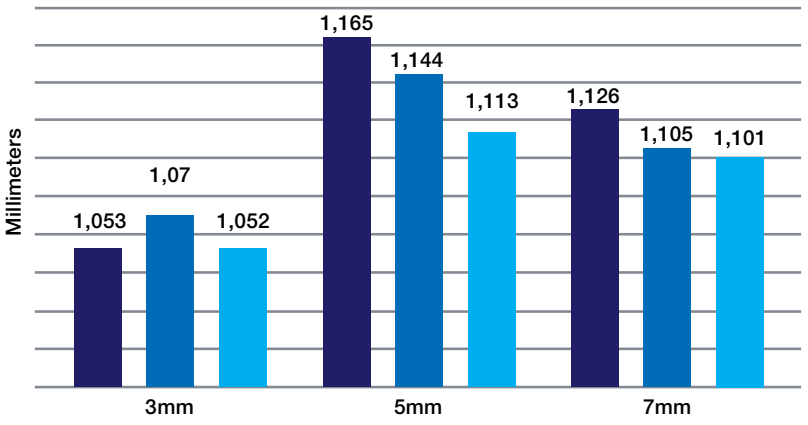

- K-Files - PathFiles - WaveOne Gold Glider

Figure 1. Minimum remaining dentine thickness after glide path preparation using three different techniques.

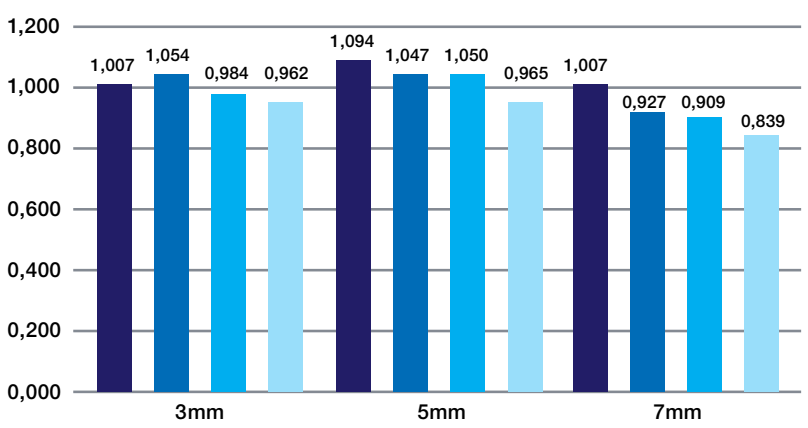

- K-Files - PathFiles WaveOne Gold Glider No Glide Path

Figure 2. Minimum remaining dentine thickness after final preparation with WaveOne Gold Primary instrument in combination with different glide path/no glide path techniques.
When minimum remaining dentine thickness was evaluated after preparation with the Primary WaveOne Gold instrument, no significant difference between groups was found at the three levels from the root apex.

Although not statistically significant, the group that performed most poorly on the ability to preserve dentine thickness when mean remaining dentine thickness over all three levels was compared, was the group in which no glide path had been prepared.

The findings are similar to those of Elnaghy and Elsaka, ${ }^{18}$ who concluded that there was no significant difference in the remaining dentine thickness after preparation with ProTaper Next in combination with different glide path techniques. Elnaghy and Elsaka ${ }^{18}$ also found that where no glide path had been prepared before final instrumentation with ProTaper Next, the amount of dentine preserved was significantly less than in the groups where a glide path had been prepared before final preparation, irrespective of the glide path technique.

According to Lim and Stock ${ }^{19}$ the minimum desired dentine thickness post-instrumentation was set at $0.3 \mathrm{~mm}$. This minimum value was determined on the basis of sufficient resistance to obturation forces, as well as to forces occurring with normal function.

Caputo and Standlee ${ }^{20}$ found in 1976 that $1 \mathrm{~mm}$ sound dentine was needed around a post for adequate resistance to root fracture. Although statistically not significantly different, most of the canals in the three glide path preparation groups had a remaining dentine thickness of over $1 \mathrm{~mm}$ when this dentine thickness was measured post-instrumentation.

There was no statistically significant difference in the amount of remaining dentine between different glide path groups in combination with final preparation using the WaveOne Gold Primary instrument ( $p>0.05)$.

\begin{tabular}{|c|c|c|c|c|c|}
\hline $\begin{array}{l}\text { Preparation } \\
\text { method }\end{array}$ & Number & Mean & $\begin{array}{l}\text { Standard } \\
\text { deviation }\end{array}$ & $\begin{array}{l}\text { Minimum } \\
\text { value }\end{array}$ & $\begin{array}{l}\text { Maximum } \\
\text { value }\end{array}$ \\
\hline K-files & 45 & $1.11^{\mathrm{a}}$ & 0.16 & 0.88 & 1.40 \\
\hline PathFiles & 45 & $1.13^{\mathrm{a}}$ & 0.21 & 0.92 & 1.64 \\
\hline $\begin{array}{l}\text { WaveOne } \\
\text { Gold Glider }\end{array}$ & 45 & $1.09^{a}$ & 0.18 & 0.83 & 1.42 \\
\hline
\end{tabular}

Mean values with the same superscript letters were not statistically different at $\mathrm{p}<0.05$

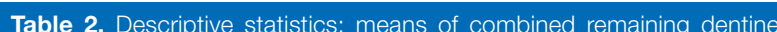
thickness after final preparation with the Primary WaveOne Gold instrument in combination with the different glide path preparation techniques

Preparation Number Mean Standard Minimum Maximum method Number Mean deviation value value
men

$\begin{array}{llllll}\text { K-files } & 45 & 1.04^{\mathrm{a}} & 0.16 & 0.78 & 1.28\end{array}$

$\begin{array}{llllll}\text { PathFiles } & 45 & 1.01^{\mathrm{a}} & 0.22 & 0.75 & 1.47\end{array}$

$\begin{array}{llllll}\text { WaveOne } & 45 & 0.98^{\mathrm{a}} & 0.17 & 0.78 & 1.27\end{array}$

Gold Glider

No glide

45

$0.92^{\mathrm{a}} \quad 0.13$

0.75

1.26

path

Mean values with the same superscript letters were not statistically different at $p<0.05$. 
However, not having a glide path prior to final canal preparation with the Primary WaveOne Gold instrument resulted in the most unfavourable dentine preservation.

\section{CONCLUSION}

Within the limitations of the study, it appears that all of the glide path techniques in combination with the Primary WaveOne Gold instrument preserved the dentine conservatively.

Although not statistically significant, the least conservative dentine preservation was observed in the group where no glide path was prepared prior to final instrumentation with the Primary WaveOne Gold instrument.

\section{Acknowledgements}

The authors thank Dentsply Sirona for donating the files for this study and the Department of Odontology, University of Pretoria, South Africa for supporting this project. The authors thank the South African National Centre for Radiography and Tomography, Radiation Science, South African Nuclear Energy Corp. for the use of the Micro-Focus X-ray Tomography Facility, particularly $\mathrm{Mr}$ Jacobus Hoffman for his time and assistance with the reconstruction of micro-focus $x$-ray images. The authors also thank Prof. H.S. Schoeman for his valuable support with statistical analysis. The authors declare no conflict of interest related to this study.

\section{References}

1. Berutti E, Negro AR, Lendini M, Pasqualini D. Influence of manual preflaring and torque on the failure rate of ProTaper rotary instruments. J Endod. 2004; 30(4): 228-30.

2. Kakehashi S, Stanley H, Fitzgerald R. The effects of surgical exposures of dental pulps in germ-free and conventional laboratory rats. Oral Surg Oral Med Oral Pathol. 1965; 20(3): 340-9.

3. Schilder $\mathrm{H}$. Cleaning and shaping the root canal. Dent Clin North Am. 1974; 18: 269-96.

4. Peters OA. Current challenges and concepts in the preparation of root canal systems: a review. J Endod. 2004; 30(8): 559-67.

5. Abou-Rass M, Frank AL, Glick DH. The anticurvature filing method to prepare the curved root canal. J Am Dent Assoc. 1980; 101(5): 792-4.

6. Reeh ES, Messer HH, Douglas WH. Reduction in tooth stiffness as a result of endodontic and restorative procedures. J Endod. 1989; 15(11): 512-6.

7. Walia $\mathrm{H}$, Brantley WA, Gerstein $\mathrm{H}$. An initial investigation of the bending and torsional properties of Nitinol root canal files. J Endod. 1988; 14(7): 346-51.

8. Glosson CR, Haller RH, Dove SB, Carlos E. A comparison of root canal preparations using $\mathrm{Ni}$ - $\mathrm{Ti}$ hand, $\mathrm{Ni}$-Ti engine-driven, and K-Flex endodontic instruments. J Endod. 1995; 21(3): 146-51.

9. Khatavkar R, Hegde V. Importance of patency in endodontics. Endodontology 2010; 22: 85-91.

10. West J. Endodontic update 2006. JERD. 2006; 18(5): 280-300.

11. Hashem AAR, Ghoneim AG, Lutfy RA, Foda MY, Omar GAF. Geometric analysis of root canals prepared by four rotary NiTi shaping systems. J Endod. 2012; 38(7): 996-1000.

12. Bernardes RA, Rocha EA, Duarte MAH, et al. Root canal area increase promoted by the EndoSequence and ProTaper systems: comparison by computed tomography. J Endod. 2010; 36(7): 1179-82.
13. Pasternak-Júnior B, Sousa-Neto M, Silva R. Canal transportation and centring ability of RaCe rotary instruments. Int Endod J. 2009; 42(6): 499-506.

14. Marzouk AM, Ghoneim AG. Computed tomographic evaluation of canal shape instrumented by different kinematics rotary nickel-titanium systems. J Endod. 2013; 39(7): 906-9.

15. Dowker SE, Davis GR, Elliott JC. X-ray microtomography: nondestructive three-dimensional imaging for in vitro endodontic studies. Oral Surg Oral Med Oral Pathol Oral Radiol Endodont. 1997; 83(4): 510-6.

16. Rhodes J, Ford T, Lynch J, Liepins P, Curtis R. Micro-computed tomography: a new tool for experimental endodontology. Int Endod J. 1999; 32(3): 165-70.

17. Schneider SW. A comparison of canal preparations in straight and curved root canals. Oral Surg Oral Med Oral Pathol and Radiol. 1971; 32(2): 271-5.

18. Elnaghy AM, Elsaka SE. Evaluation of root canal transportation, centering ratio, and remaining dentin thickness associated with ProTaper Next instruments with and without glide path. J Endod. 2014; 40(12): 2053-6.

19. Lim S, Stock C. The risk of perforation in the curved canal: anticurvature filing compared with the stepback technique. Int Endod J. 1987; 20(1): 33-9.

20. Caputo A, Standlee J. Pins and posts - why, when and how. Dent Clin North Am. 1976; 20(2): 299-311. 